\title{
Incumbency Advantages, Distribution Networks and Exclusivity - Evidence from the European Car Markets*
}

\author{
Laura Nurski ${ }^{\dagger} \quad$ Frank Verboven ${ }^{\ddagger}$
}

February 2014

\begin{abstract}
This paper investigates the role of distribution networks in explaining incumbency advantages in the European car market. We compare three approaches to incorporate the size of distribution networks in discrete choice models of product differentiation: as an extra product characteristic, as a new dimension of product differentiation in a nested logit framework, or as a measure of the expected travel cost under a spatial Poisson distribution of locations. We obtain robust conclusions across all three approaches: distribution networks play an important role in explaining car producers' market shares, but they only appear to explain part of the bias towards domestic brands in the car market. We also report on an ongoing research project where we analyze the role of distribution networks at a much more detailed local market level, and investigate the specific role of exclusive dealing as a possible entry barrier.
\end{abstract}

Keywords: Distribution Networks, Incumbency Advantages, Vertical restraints, Exclusivity, Automotive industry

JEL Classification: L42, L62, L14

*We thank Lieselot Baert for excellent research assistance in assembling the European car dealer data. We gratefully acknowledge financial support from University of Leuven Program Financing Grant and Science Foundation - Flanders (FWO).

${ }^{\dagger}$ University of Leuven and Ph.D. Fellow of the Research Foundation - Flanders (FWO). Email: Laura.Nurski@econ.kuleuven.be.

$\ddagger$ University of Leuven and C.E.P.R. (London). Email: Frank.Verboven@econ.kuleuven.be. 


\section{Introduction}

Car manufacturers across the world make use of a variety of vertical restraints to organize their dealer networks. In European countries two forms of exclusivity are common. Territorial exclusivity provides dealers the right to sell a certain brand in a designated territory without competition from other dealers selling the same brand. Brand exclusivity, usually referred to as exclusive dealing, provides manufacturers the right to mandate their dealers not to sell competing brands within the same outlet. Theoretical work has stressed that incumbents may use this second form of exclusivity to foreclose new entry. When dealers cannot sell other brands, new entrants are forced to set up their own costly distribution networks; see for example, Aghion and Bolton (1987) and Segal and Whinston (2000). In ongoing work we empirically analyse the incentives of incumbent car producers to foreclose entry through exclusive dealing. We take into account that new entrants may compensate the incumbents and their dealers for not signing exclusive dealing contracts (Nurski and Verboven, 2013). This work is based on a rich dataset on demand and dealer locations at the level of local markets in one country (Belgium).

In the present paper we address a preliminary question using more aggregate data for a panel of nine European countries during 2000-2009. We ask to what extent the size of car producers' distribution networks contributes to explaining the car producers' market shares. We find that the distribution networks play an important role, although they only appear to explain part of the bias for domestic brands as observed in countries with local car producers.

Analyzing the role of distribution networks on demand is of broader interest to understand the mechanisms behind incumbency advantages emphasized in industrial organization, and behind market entry or penetration costs recently emphasized in international trade. ${ }^{1}$ We therefore first present three possible approaches on how one may incorporate distribution networks in discrete choice models of product differentiation. We then present the data and empirical results. Finally, we conclude and report on an ongoing research project that aims to investigate the subsequent question whether exclusive dealing acts as a specific entry barrier in the car industry.

\footnotetext{
1 Geroski (1995) discusses the stylized fact that even successful new entrants require a considerable amount of time to reach market shares comparable to incumbents. Berger and Dick (2007) and Bronnenberg et al. (2009) provide recent analyses of early mover advantages and the persistence of market shares. In international trade, Das et al. (2007) provide an empirical analysis of market entry costs, and Arkolakis (2010) provides a model to analyze the trade implications of these costs.
} 


\section{Incorporating distribution networks in discrete choice models}

Discrete choice models have become very popular to estimate substitution patterns between differentiated products. Berry (1994) and Berry et al. (1995) showed how to estimate these models with aggregate data on sales per product. Most work has focused on the role of price and product characteristics, and some work also considered the impact of advertizing. In this section we show how one may incorporate the role of distribution networks. For clarity of exposition, we base the discussion on a simple logit model where consumers have uncorrelated preferences for different products. In our empirical analysis we extend the model to incorporate the possibility that consumers have correlated preferences for products of the same segment and subsegment.

A total number of $L$ potential consumers choose among $J$ differentiated products, $j=$ $1, \ldots, J$, or alternatively they may choose not to buy in which case they purchase the outside good $j=0$. The indirect utility of an individual $i$ for product $j$ is given by

$$
u_{i, j}=\delta_{j}+\varepsilon_{i, j}
$$

The first part is the mean utility $\delta_{j}$, common to all consumers:

$$
\delta_{j} \equiv x_{j} \beta+\alpha p_{j}+\xi_{j}
$$

This depends on a vector of observed product characteristics $x_{j}$ (such as horsepower), price $p_{j}$ and an unobserved quality term $\xi_{j}$. The second part is the individual-specific deviation around that mean $\varepsilon_{i, j}$, modelled as a mean zero random variable. In the simple logit model, $\varepsilon_{i, j}$ is distributed i.i.d. extreme value. This assumption implies that consumers substitute symmetrically to other products when one product becomes less attractive.

Assuming that consumers choose the product $j=0,1, \ldots, J$ that gives the highest utility, one can obtain the individual choice probabilities or approximately the aggregate market shares $s_{j}$ for every product $j$ (where the market shares are sales divided by the potential number of consumers $L$ ). Following Berry (1994), this gives rise to the following simple demand system:

$$
\frac{s_{j}}{s_{0}}=\frac{\exp \left(\delta_{j}\right)}{\exp \left(\delta_{0}\right)} \quad j=1, \ldots, J,
$$

where $s_{0}=1-\sum_{j=1}^{J} s_{j}$. Using the above definition of $\delta_{j}$ for $j=1, \ldots, J$ and normalizing 
$\delta_{0}=0$ for the outside good, one obtains the estimating equation

$$
\ln s_{j} / s_{0}=x_{j} \beta+\alpha p_{j}+\xi_{j}
$$

There are several ways to incorporate the role of distribution networks in this demand framework. An obvious first approach would simply consist of including the number of dealers of the product's brand, $N_{j}$, as an additional variable in the product characteristics vector $x_{j}$. In this case, consumers have a (mean) valuation for the number of dealers per se. While this approach is attractive because of its simplicity, it entails some difficulties, such as the choice of functional form in which $N_{j}$ should enter. A practical difficulty also arises when the model is estimated with pooled data over different countries to exploit cross-country variation, as in our application. In this case, the number of dealers of a given brand may systematically differ across countries because of differences in market size or population density. An ad hoc solution is to normalize the number of dealers per country, for example by dividing it by the country average, $N_{j} / \bar{N}$. We follow this as our first approach to incorporate distribution networks.

Our second and third approach incorporate the number of dealers in a different way, giving rise to natural functional forms without requiring an arbitrary normalization of the number of dealers. Our second approach explicitly starts from a more disaggregate choice level. The consumer's unit of choice is no longer the product (car model) $j$, but rather the dealer $k$ selling product $j$. Consumers may have correlated preferences for dealers $k$ selling the same product $j$ according to a nested logit model. More specifically, suppose that each product $j$ is sold by $N_{j}$ dealers, so $k=1, \ldots, N_{j}$. Individual $i$ 's utility for dealer $k$ selling product $j$ is given by

$$
u_{i, k j}=\delta_{j}+\varsigma_{i, j}+\left(1-\sigma_{J}\right) \varepsilon_{i, k j}
$$

This specification assumes that consumers have the same mean utility for all dealers of the same product, $\delta_{k j}=\delta_{j}$. The individual-specific deviation around that mean is the sum of two random variables $\varepsilon_{i, k j}$ and $\varsigma_{i, j}$, which follow the distributional assumptions of a nested logit model (Cardell, 1997). First, $\varepsilon_{i, k j}$ is an idiosyncratic valuation that is distributed i.i.d. extreme value across products and dealers. Second, $\varsigma_{i, j}$ is a common valuation across all dealers of product $j$, with the unique distribution such that $\varsigma_{i, j}+\left(1-\sigma_{J}\right) \varepsilon_{i, k j}$ is also an extreme value random variable. The parameter $\sigma_{J}$, with $0 \leq \sigma_{J} \leq 1$, measures the degree of preference correlation for dealers $k$ selling the same product $j$. If $\sigma_{J}=1$, then dealers selling the same product are perfect substitutes. In contrast, if $\sigma_{J}=0$, dealers of the same product are equally differentiated as dealers from different products (if they belong to the same subgroup). 
Following similar steps as in Berry (1994), the nested logit model gives rise to the following inverted market share system

$$
\frac{s_{k j}}{s_{0}}\left(\frac{s_{k j}}{s_{j}}\right)^{-\sigma_{J}}=\frac{\exp \left(\delta_{j}\right)}{\exp \left(\delta_{0}\right)}, \quad k=1, \ldots, N_{j}, \quad j=1, \ldots, J
$$

where $s_{k j}$ is the market share of dealer $k$ of product $j$, and $s_{j}=\sum_{k=1}^{N_{j}} s_{k j}$ is the market share of product $j$. In contrast with Berry (1994), we do not observe market shares at the level of the dealer $\left(s_{k j}\right)$, but only at the level of the product $\left(s_{j}\right)$. However, since we assumed $\delta_{k j}=\delta_{j}$, we can easily aggregate the market shares up to the level of the product $j$ as in Ben-Akiva and Lerman (1985). After some rearrangements, this gives

$$
\frac{s_{j}}{s_{0}}=N_{j}^{1-\sigma_{J}} \frac{\exp \left(\delta_{j}\right)}{\exp \left(\delta_{0}\right)}
$$

Since $\delta_{0}=0$, the estimating equation becomes

$$
\ln s_{j} / s_{0}=x_{j} \beta+\alpha p_{j}+\left(1-\sigma_{J}\right) \ln N_{j}+\xi_{j}
$$

This specification extends the base model in (1) with one additional variable, the logarithm of the number of dealers, $\ln N_{j}$. The coefficient of this variable may be expected to be between 0 and 1 , and has the interpretation of preference correlation for dealers of the same product. If consumers perceive dealers of a given product as perfect substitutes $\left(\sigma_{J}=1\right)$, the coefficient of $\ln N_{j}$ is 0 . If consumers have uncorrelated preferences for dealers of the same product $\left(\sigma_{J}=0\right)$, the coefficient is 1 . Note that one can easily generalize this approach to include nests at higher levels such as segments (as we do below) or to include random coefficients on continuous variables: in both cases, one simply uses standard models and adds $\ln N_{j}$ as an additional variable.

A third approach to incorporate the number of dealers starts from the assumption that consumers value the distance to the nearest dealer. The total price for consumer $i$ purchasing product $j$ is equal to the purchase price plus the expected travel cost to the nearest dealer, $p_{j}+k d\left(N_{j}\right)$, where $k$ is the travel cost per unit of distance and $d\left(N_{j}\right)$ is the expected distance of a consumer to the nearest dealer selling product $j$, a decreasing function of the number of dealers in the country. If one assumes that consumer and dealer locations follow a spatial Poisson process, then the expected distance to the nearest dealer follows a "square root law" in dealer density, $d\left(N_{j}\right)=0.5 \sqrt{M / N_{j}}$, where $M$ is total surface area in the country. Kolesar and Blum (1973) provide a derivation for this square root law, and Ferrari et al. (2010) apply it to ATM demand. Replacing $p_{j}$ by $p_{j}+k 0.5 \sqrt{M / N_{j}}$ in (1), we obtain the 
following estimating equation:

$$
\ln s_{j} / s_{0}=x_{j} \beta+\alpha p_{j}+\gamma\left(0.5 \sqrt{M / N_{j}}\right)+\xi_{j},
$$

where $\gamma=\alpha k$.

In practice, consumers and dealers may not be spread randomly across a region according to a spatial Poisson distribution, so that the square root law does not hold. Ferrari et al. (2010) assess this assumption for ATM locations, and they find evidence that the square root law is a good approximation for the expected distance to the nearest dealer in their application. For our application on dealer locations, we used a Clarke-Evans test for complete spatial randomness (based on the detailed dealer location data for Belgium, used in Nurski and Verboven (2013)). The results from this test-statistic (not reported) show that for 28 of the 32 brands we cannot reject the hypothesis that the dealers are Poisson distributed. There is dispersion for 3 brands (Opel, Peugeot and Volvo), while there is clustering for 1 brand (Subaru).

To summarize, we consider three approaches to incorporate the size of distribution networks. First, the characteristics approach simply includes the normalized number of dealers $N_{j} / \bar{N}$ in the characteristics vector $x_{j}$, and the coefficient has the interpretation of a value for the number of dealers per se. Second, the nested logit approach includes the logarithm of the number of dealers $\ln N_{j}$. Its coefficient captures the extent of preference correlation across dealers of the same product. Third, the spatial Poisson approach includes the expected

distance to the nearest dealer $0.5 \sqrt{M / N_{j}}$. Its coefficient reflects the travel cost per unit of distance. Note that there may still be other approaches to model the number of dealers. For example, the number of dealers of a certain brand may affect the likelihood that this brand enters a consumers consideration set, similar to Goeree (2008)'s approach to modeling the impact of advertizing.

\section{Empirical analysis}

\subsection{Data}

We combine two different datasets. Our first dataset is from JATO, and contains information on sales, list prices and product characteristics (such as horsepower and fuel economy) of all cars sold during 2000-2009 in nine European countries: Belgium, France, Germany, Greece, Italy, the Netherlands, Portugal, Spain, and the United Kingdom. While the original data are at the very detailed level of the model, engine variant and version (trim level), we aggregate 
the sales information to the model level (e.g. Golf), and select the base model to define the price and product characteristics. Each model can be assigned to a brand and a firm. For example, the Golf and Passat are of the Volkswagen brand and the Ibiza is of the Seat brand, and both of these brands belong to the VW Group. Each model can also be assigned to one of seven possible marketing segments: subcompact, compact, intermediate, standard, luxury, SUV and sports. Finally, each model can be assigned to a country of origin (as perceived by consumers). For example, the Volkswagen brands are perceived as German and the Seat brands as Spanish. Based on this information, we construct a dummy variable to distinguish between domestic and foreign brands. For example, Volkswagen is a domestic brand in Germany, and a foreign brand in the other eight countries of our dataset. For more details on the data (for a shorter period up to 2006) we refer to Grigolon and Verboven (2013).

Our second data set is from HWB (Harbour Wade Brown). It contains information on the total number of dealers per brand, for the same period 2000-2009 in the same nine countries. Dealers are defined as direct dealers, independent dealers and indirect agents. Almost all dealers offer both sales and after-sales services. We combine the dealer data with the dataset on sales, prices and product characteristics, using the variable brand as a common key.

Table 1 shows summary statistics of the main variables. For example, the average sales of a model in a market is 6113 , with a large standard deviation of 14533 . The average number of dealers of a brand in a market is 418 , again with a large standard deviation of 704 . Note that this large variation in the number of dealers is due to both between-brand variation and within-brand variation (variation per brand across countries) ${ }^{2}$ Hence, we identify the effect of the number of dealers on sales from both between-brand variation and within-brand variation.

\subsection{Specification and estimation}

We extend the above demand model to a two-level nested logit model. The upper level defines the set of products in groups $g$ according to the different marketing segments. The lower level further divides each group in subgroups $h$ of $g$, which refers to the country of origin: domestic of foreign brand. We estimate the model for a panel of products (car models) $j$, observed in different markets (country-year combinations) $t$. The nested logit gives rise to the following estimating equation:

$$
\ln s_{j t} / s_{0 t}=x_{j t} \beta+\gamma f\left(N_{j t}\right)+\alpha p_{j t}+\sigma_{H G} \ln s_{j \mid h g t}+\sigma_{G} \ln s_{h g \mid g t}+\xi_{j}+\xi_{t}+\xi_{j t},
$$

\footnotetext{
${ }^{2}$ For example, in 2005 the normalized number of dealers $N_{j} / \bar{N}$ had a mean of 0.97 , an overall standard deviation of 0.78 , a between-brand standard deviation of 0.62 and a within-brand standard deviation of 0.56 .
} 
Table 1: Summary statistics

\begin{tabular}{l|rr} 
& Mean & St. Dev. \\
\hline price/income & 1.18 & 0.86 \\
sales & 6113.39 & 14533.12 \\
horsepower $(\mathrm{kW})$ & 91.82 & 41.43 \\
fuel cost $(€ / 100 \mathrm{~km})$ & 0.08 & 0.03 \\
width & 174.64 & 8.50 \\
height & 149.39 & 12.74 \\
foreign & 0.91 & 0.29 \\
months available & 9.74 & 2.59 \\
dealers $\left(N_{j}\right)$ & 417.51 & 703.75 \\
$N_{j} / \bar{N}$ & 1.00 & 0.83 \\
$\ln N_{j}$ & 5.35 & 1.09 \\
$0.5 \sqrt{M / N_{j}}$ & 0.50 & 0.26
\end{tabular}

Notes: The total number of observations (models/markets) is 18,021 . The number of markets is 90 (9 countries during 2000-2009), the average number of models per market is 200 .

where $s_{j t}$ is the market share of product $j$ in the potential market, $s_{0 t}$ is the market share of the outside good in the potential market $]^{3} s_{j \mid h g t}$ is the market share of the product in its subgroup $h g$, and $s_{h \mid g t}$ is the market share of the subgroup in the group $g$. The expression $f\left(N_{j}\right)$ is a measure of the number of dealers, i.e. $N_{j} / \bar{N}, \ln N_{j}$ or $0.5 \sqrt{M / N_{j}}$ in our above set-up. The nesting parameters $\sigma_{H}$ and $\sigma_{G}$ (with $0 \leq \sigma_{G} \leq \sigma_{H G} \leq 1$ ) measure the degree of preference correlation for products of the same subgroup and group. For example, if $\sigma_{H}=1$, consumers perceive all brands of the same subgroup as perfect substitutes. As another example, if $\sigma_{H}=\sigma_{G}=0$, there is not preference correlation within subgroups and groups, so the model simplifies to a logit model. Note that our second approach to incorporate distribution networks effectively results in a three-level nested logit, implying the restriction $0 \leq \sigma_{G} \leq \sigma_{H G} \leq \sigma_{J} \leq 1$.

We account for a full-set of product fixed effects $\xi_{j}$, capturing time-invariant unobserved quality for each car model. We also account for a full set of market fixed effects $\xi_{t}$, which captures macro-economic shocks specific to every country and year. To estimate the model, we adopt the common identification assumption that the product characteristics $x_{j t}$ are exogenous, uncorrelated with the error term $\xi_{j t}$. We also assume that the number of dealers $N_{j t}$ is uncorrelated with $\xi_{j t}$. While both $x_{j t}$ and $N_{j t}$ are chosen by the firms, we control for time-invariant quality through $\xi_{j}$, so we only assume there is no correlation with unobserved

\footnotetext{
${ }^{3}$ The potential market is set equal to the total number of households.
} 
quality that changes over time or differs across markets. In contrast, we allow price $p_{j t}$ and the market share variables $s_{j \mid h g t}$ and $s_{h \mid g t}$ to be endogenous. To account for their endogeneity we follow Berry et al. (1995) and use sums of other product characteristics of the same firm and of other firms as instruments. We also add sums of other product characteristics by segment and subsegment as instruments.

\subsection{Results}

Table 2 shows the empirical results. The first column shows the parameter estimates of the nested logit model without accounting for the size of the dealer network. Price and fuel cost have a significant negative effect on demand, while horsepower, width and height have a significant positive effect. Consumers put a significant negative valuation on brands of foreign origin, showing the presence of a home bias. The nesting parameters satisfy the restrictions for consistency with random utility maximization in a two-level nested logit, $0<\sigma_{G}=0.53<_{H G}=0.71<1$. They indicate that there is strong segmentation according to the marketing segments, and significant further segmentation between domestic and foreign brands.

The second to fourth columns show the results after controlling for the size of the dealer network through each of our three measures. In all three cases the dealer variable enter significantly with the expected sign. The normalized number of dealers $\left(N_{j} / \bar{N}\right)$ has a positive effect, suggesting that consumers valuation dealer availability $!^{4}$ The coefficient for the $\log$ number of dealers $\left(\ln N_{j}\right)$ is also positive. Its magnitude is 0.24 , so that $\sigma_{J}=0.76$, which satisfying the restrictions $0<\sigma_{G}<\sigma_{H G}<\sigma_{J}<1$ of a three-level nested logit model. Finally, the square root of surface area per dealer $\left(0.5 \sqrt{M / N_{j}}\right)$ has a negative coefficient, suggesting consumers put a negative valuation on brands with a higher expected travel cost ${ }^{5}$ The dealer elasticity ranges between 0.2 and 0.5 across the three models, suggesting that a $1 \%$ increase in the number of dealers (i.e. an increase of 4.2 dealers on average) is associated with an increase in market shares of $0.2 \%$ to $0.5 \%$ (or 12 to 31 extra cars sold per model).

Controlling for the size of the brands' distribution networks leads to lower estimates of the nesting parameters $\sigma_{G}$ and $\sigma_{H G}$. This indicates that the extent of market segmentation is overestimated in the model without dealer networks in column 1. More interestingly, after

\footnotetext{
${ }^{4}$ As a sensitivity check, we also estimated the dealer effects interacted with a segment dummies. We found that for most segments the dealer effects do not differ significantly from the average effect of 0.197 . The exceptions are for the standard segment, with a stronger effect of 0.309, and the SUV and sports segments, with smaller effects of respectively 0.060 and 0.135 .

${ }^{5}$ Dividing the distance coefficient by the price coefficient (unnormalized for income) would imply a travel cost of $106 €$ per $\mathrm{km}$. This includes the cost of all expected future service and repair trips, but it may also capture non-transportation related factors omitted from this model.
} 
controlling for the size of the distribution networks, the negative valuation for brands of foreign origin slightly drops (in absolute value), but it remains significant and quantitatively important. This suggests that distribution networks explain only part of the consumers' home bias (i.e. their preference for domestic over foreign brands), but it remains for an important part unexplained. In sum, these findings show that dealer networks are an important factor contributing to the car producers' market shares, but they only partly explain much of the bias towards domestic brands.

Table 2: Nested Logit Demand Results

\begin{tabular}{|c|c|c|c|c|}
\hline & (1) & $(2)$ & $(3)$ & (4) \\
\hline \multirow{2}{*}{ price/income } & -0.973 & -0.801 & -0.822 & -0.935 \\
\hline & $(0.104)$ & $(0.103)$ & $(0.102)$ & $(0.103)$ \\
\hline \multirow[t]{2}{*}{ horsepower } & 0.008 & 0.007 & 0.008 & 0.009 \\
\hline & $(0.001)$ & $(0.001)$ & $(0.001)$ & $(0.001)$ \\
\hline \multirow[t]{2}{*}{ fuel cost } & -2.307 & -4.750 & -4.710 & -4.392 \\
\hline & $(1.001)$ & $(1.028)$ & $(0.957)$ & $(0.868)$ \\
\hline \multirow[t]{2}{*}{ width } & 0.013 & 0.012 & 0.011 & 0.008 \\
\hline & $(0.005)$ & $(0.006)$ & $(0.006)$ & $(0.005)$ \\
\hline \multirow[t]{2}{*}{ height } & 0.011 & 0.018 & 0.014 & 0.008 \\
\hline & $(0.003)$ & $(0.004)$ & $(0.004)$ & $(0.003)$ \\
\hline \multirow[t]{2}{*}{ foreign } & -0.379 & -0.343 & -0.303 & -0.313 \\
\hline & $(0.074)$ & $(0.064)$ & $(0.061)$ & $(0.066)$ \\
\hline$N_{j} / \bar{N}$ & & $\begin{array}{c}0.198 \\
(0.026)\end{array}$ & & \\
\hline $\ln N_{j}\left(\sigma_{J}\right)$ & & & $\begin{array}{c}0.188 \\
(0.037)\end{array}$ & \\
\hline $0.5 \sqrt{M / N_{j}}(\gamma)$ & & & & $\begin{array}{l}-0.266 \\
-0.174\end{array}$ \\
\hline $\ln s_{j \mid h g t}\left(\sigma_{H G}\right)$ & $\begin{array}{c}0.655 \\
(0.059)\end{array}$ & $\begin{array}{c}0.460 \\
(0.066)\end{array}$ & $\begin{array}{c}0.557 \\
(0.070)\end{array}$ & $\begin{array}{c}0.693 \\
(0.061)\end{array}$ \\
\hline $\ln s_{h g \mid g t}\left(\sigma_{G}\right)$ & $\begin{array}{c}0.528 \\
(0.066)\end{array}$ & $\begin{array}{c}0.352 \\
(0.068)\end{array}$ & $\begin{array}{c}0.450 \\
(0.068)\end{array}$ & $\begin{array}{c}0.564 \\
(0.061)\end{array}$ \\
\hline
\end{tabular}

Notes: The total number of observations (models/markets) is 18,021 . Fixed effects for products (car models) and markets (countries and years) are included. Standard errors (clustered by model) are in parentheses. 


\section{Conclusions}

We have suggested various approaches to incorporate the role of distribution networks in standard discrete choice models of product differentation. Our empirical results give robust conclusions across the different approaches. We obtain the following two main findings. First, distribution networks appear to be an important determinant of car producers' market

shares. Second, distribution networks only explain part of the home bias, i.e. the larger market shares of car producers in their home markets.

In sum, distribution networks matter for building market share advantages, but not necessarily much to the advantage of the domestic producers. Having established the importance of distribution networks, a next question is to what extent exclusive dealing plays a specific role in deterring entry by new car producers from Asia or other countries. In ongoing research, we explore this question in detail (Nurski and Verboven, 2013). We collected sales data for Belgium at the level of the local market (town) and match these data to dealer locations (both single-brand and multi-brand dealers). We estimate a spatial demand model to assess the entry-deterring incentive of exclusive dealing, when new entrants can compensate incumbents and their dealers for not signing exclusive dealing contracts. We compare this incentive with the efficiency motivation for exclusive dealing (demand-enhancing because it protects investments in sales and after-sales serivices), and compute the welfare effects from removing exclusive dealing.

\section{References}

Aghion, Philippe and Patrick Bolton, "Contracts as a Barrier to Entry," American Economic Review, June 1987, 77 (3), pp. 388-401.

Arkolakis, Costas, "Market Penetration Costs and the New Consumers Margin in International Trade," Journal of Political Economy, 2010, 118 (6), 1151-1199.

Ben-Akiva, Moshe E. and Steven R. Lerman, Discrete choice analysis: theory and application to predict travel demand, Vol. 9, The MIT press, 1985.

Berger, Allen N. and Astrid A. Dick, "Entry into Banking Markets and the Early-Mover Advantage," Journal of Money, Credit and Banking, June 2007, 39 (4), 775-807.

Berry, Steven, James Levinsohn, and Ariel Pakes, "Automobile Prices in Market Equilibrium," Econometrica, July 1995, 63 (4), 841-90. 
Berry, Steven T., "Estimating Discrete-Choice Models of Product Differentiation," RAND Journal of Economics, Summer 1994, 25 (2), 242-262.

Bronnenberg, Bart J, Sanjay K Dhar, and Jean-Pierre H Dubé, "Brand history, geography, and the persistence of brand shares," Journal of political Economy, 2009, 117 (1), 87-115.

Cardell, N Scott, "Variance components structures for the extreme-value and logistic distributions with application to models of heterogeneity," Econometric Theory, 1997, 13 (02), 185-213.

Das, Sanghamitra, Mark J Roberts, and James R Tybout, "Market entry costs, producer heterogeneity, and export dynamics," Econometrica, 2007, 75 (3), 837-873.

Ferrari, Stijn, Frank Verboven, and Hans Degryse, "Investment and Usage of New Technologies: Evidence from a Shared ATM Network," American Economic Review, June 2010, 100 (3), 1046-79.

Geroski, Paul. A., "What do we know about entry?," International Journal of Industrial Organization, December 1995, 13 (4), 421-440.

Goeree, Michelle Sovinsky, "Limited Information and Advertising in the U.S. Personal Computer Industry," Econometrica, 09 2008, 76 (5), 1017-1074.

Grigolon, Laura and Frank Verboven, "Nested Logit or Random Coefficients Logit? A Comparison of Alternative Discrete Choice Models of Product Differentiation.," Review of Economics and Statistics, 2013, forthcoming.

Kolesar, Peter and Edward H Blum, "Square root laws for fire engine response distances," Management Science, 1973, 19 (12), 1368-1378.

Nurski, Laura and Frank Verboven, "Exclusive dealing as a barrier to entry? Evidence from automobiles," 2013. Mimeo.

Segal, Ilya R. and Michael D. Whinston, "Naked Exclusion: Comment," American Economic Review, March 2000, 90 (1), 296-309. 